\title{
EFFECT OF MOISTURE CONTENT ON ANGLE OF REPOSE AND FRICTION COEFFICIENT OF WHEAT GRAIN
}

\author{
A. K. Zaalouk* and F. I. Zabady*
}

\begin{abstract}
This study was carried out to determine the angle of repose of three varieties of wheat (Bani Suwayf 3, Giza 168 and Seds 1) at four different levels of grian moisture contents 9.30,10.0,11.11 and12.5\% (w. b). Also to determine the coefficient of friction at the same moisture contents and four different friction surfaces of plywood, galvanized steel, plastic and rubber. The angle of repose increased linearly with the increase of moisture content for all varieties under study.The static coefficient of friction generally increased with the increase of moisture contents.
\end{abstract}

\section{INTRODUCTION}

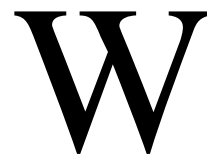

heat is one of the most important crops in Egypt and moreover is one of the worlds first important cereal crops.Strategies, which have been tried to improve the production of wheat, includes handling equipment and design of convearying and the design of stroage structures.

The root and leaves of subsp. Vulgaris are edible and an important food crop. Numerous cultivars have been selected and bred for several different characteristics; the major Cultivar groups are:

- Beetroot or taple beet (or,in the $19^{\text {th }}$ century,"blood turnip") used as a root vegetable.

- Fooder beet wurzel or mangold used as animal fooder.

- Sugar beet grown for sugar.

- Chard, a beet which has been bred for leaves instead of roots and is used as a leaf vegetable.

Beetroot can be cooked and then eaten warm with butter (after having been peeled) as a delicacy;cooked and pickled and then eaten cold as a condiment; or peeled raw and shredded and then eaten as a salad.

* Assist.Prof., Agr. Eng. Dep.,Fac .of Ag., Al-Azhar Univ. 
The leaves and stems can be steamed briefly as a vegetable, although this is preferably done with young plants. These and older leaves and stems can be sliced and stir-fried and have a flavour resembling taro leaves.The stems can also cooked with black beans to increase their nutritional value.

The red color in the beet roots (betacyanin) causes red urine and feces in some people who are unable to break it down.

The dynamic angle of repose is one of the physical properties needed for the design of material hadling systems and storage facilities for wheat.The dynamic angle of repose is the angle formed by a granular material with the horizontal as it comes to rest from sliding and rolling upon itself in an unconsolidated or losses form.

Chakraverty (1972) reported that the angle of repose is defined as the angle between the base of seeds cone and the slope of the cone formed on a free vertical fall of the grain mass to a horizontal plane.The angle of repose for wheat ranged from $23-28^{\circ}$, Barley $28-40^{\circ}$ and rice of $30-45^{\circ}$. $\mathrm{He}$ also mentioned that the coefficient of friction between granular materials is equal to the tangent of the angle of internal friction for material.The coefficient of friction depends on grain shape, surface characteristics and grain moisture content.

Kaleem et al. (1993) mentioned that the angle of repose is very important in determining the inclination angle of the machine hopper tank.

Soliman (1994) studied the effect of moisture contant on angle of repose of paddy rice.He mentioned that the dynamic angle of repose is one of the physical properties needed for the design of material handling systems and storage facilities for rice and rice products.

In the field of bulk storage,grading and handling of agricultural products,there is an urgent need for determining the friction coefficient and repose angle of some cereal crops on various surfaces. Friction characteristics are very important in determining the proper design of converying, grading and forage chopping machinery (Helmy ,1995).

Snyder et al. (1967) concluded that normal pressure and velocity have a little effect on kinetic friction coefficient of wheat on steel surface.They also indicated that increasing relative humidity of the air in contact with 
the sliding surface and /or increased grains surface moisture content increased the kinetic friction cofficient. They pointed out the necessity of controlling environmental conditions when determining the kinetic friction coefficient.

Stewart et al.(1969) stated that both dynamic and static friction coefficients are important parameters in the design of storage structures and handling equipment for granular materials .It is increased with increasing moisture content of grain.

Lawton (1980) determined the coefficient of friction of 7 materials used in the construction of agricultural silo walls for wheat and barley at different levels of moisture content. Tests were carried out by rotating angular plates on the grain surface. He reported that the friction coefficients increased with increasing moisture contents, and varied between, approximatelly,0.11for Teflon on the driest barley to,nearly, 0.5 for concrete on the wettest wheat.The coefficients with wheat were up to 0.1 higher than with barley at corresponding moisture contents

Mohsenin (1970) reported that the coefficient of friction of organic materials independent of the normal pressuer and reported this to be in agreement with what has been found for dry friction of engineering materials.

\section{MATERIAL AND METHODS}

The varieties of wheat used in this experiment were Gize 168 ,Seds 1 and Bani suwayf 3.Four different materials (surfaces) of Galvanized steel ,Plywood ,Plastic and Rubber.Four different levels of moisture content of 9.30,10,11.11 and $12.5 \%$ were considered in this study.

\section{A- Determination of repose angle:}

Letting wheat fall from a $20 \mathrm{~cm}$ height, it forms a heap.Through it's height and diameter of base.The angle of repose $(\theta)$ was measured according to the following equation :

$$
\theta=\tan ^{-1} 2 \mathrm{~h} / \mathrm{d}
$$

This test was repeated 20 times .

\section{B-Cefficient of friction (Determination of friction angle):}

Misr J. Ag. Eng., January 2009 
Coefficient of friction between the material and wheat grain is expected to be depending on material type only since wheat grain skins is very smooth. The angle of friction is the angle between a tilted plane and the horizontal plane at which a wheat grain overcomes the static friction and begins to slide down the surface of the tilted plane as it is tilted slowly and gradually.At this moment the decliation angle of the sheet was recorded. The coefficient of friction was determined according to the following equation.

$$
\mu=\tan \alpha
$$

Where :

$\alpha=$ Friction angle, (degree).

This experiment was repeated 20 times to calculate the mean external friction angle.

\section{RESULTS AND DISCUSSION}

\section{A-Angle of repose:-}

The effect of moisture content on angle of repose is shown in Fig.(1).The angle of repose increased linearly with the moisture content in all the varieties under investigation. The rate of increase of angle of repose was unifom for all varieties and conditions which were exhibited by the approximately parallel lines. The angle of repose was the highest for Giza168 followed by Bani Suwayf 3 and Sdas 1. In general the angle of repose of Gize168 changed in the range between 24.46 to 27.99 degrees depending on moisture content .Similary the angle of repose of Bani Suwayf 3 ranged from 23.72 to 27.40 degrees and for Seds 1 ranged from 23.58 to 26.29 degrees. The liner regression equations describe the relationship between the angle of erpose $(\theta, \mathrm{deg}$.) and moisture content wet basis percent $(\mathrm{M})$ for each variety and the regression coefficient of the fit were as follows.

For wheat variety Giza 168 .

$$
\theta=23.565+1.137 \mathrm{M} \quad\left(\mathbf{R}^{2}=\mathbf{0 . 9 6 9 4}\right)
$$

For wheat variety Bani Suwayf 3.

$$
\theta=22.67+1.184 \mathrm{M} \quad\left(\mathbf{R}^{2}=0.9857\right)
$$

\section{For wheat variety Seds 1.}




$$
\theta=22.85+0.893 M \quad\left(R^{2}=0.9795\right)
$$

$\multimap$ Bani Suwayf $3 \multimap-$ Giza $168 \multimap$ Sdas 1

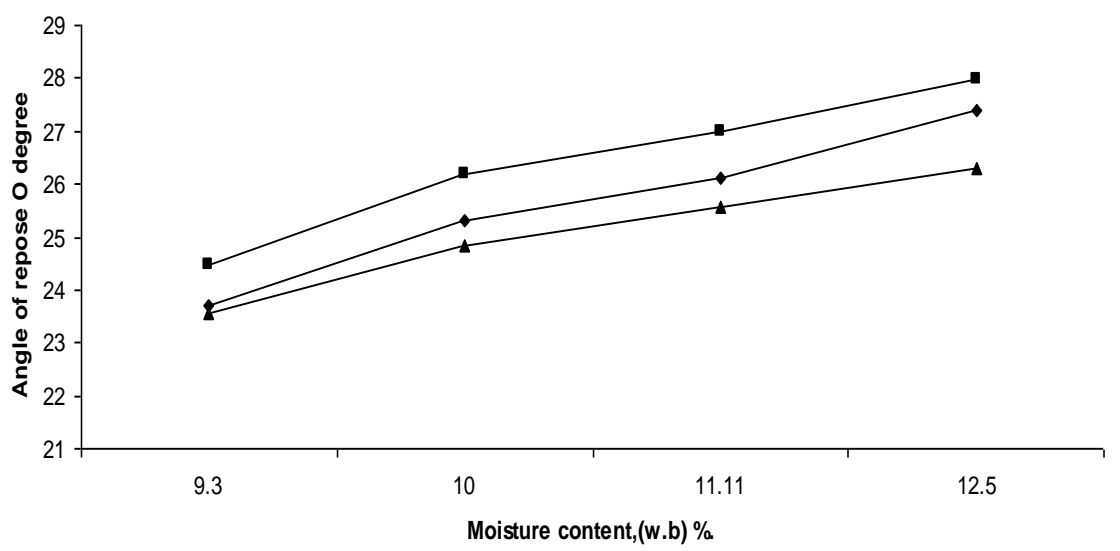

Fig.( 1 ):Effect of moisture content on angle of repose of wheat.

\section{B- Angle of friction:}

Table (1) shows the statistical analysis of data showed that the following variables and interactions had significant influence on the static coefficient of friction at one percent probability level:

Table ( 1 ) : Static coefficient of friction of three wheat varieties at the moisture conents and the four surfaces.

\begin{tabular}{|c|c|c|c|c|c|}
\hline \multirow{2}{*}{ Varieties* } & \multicolumn{2}{|l}{$\begin{array}{l}\text { Moisture * } \\
\text { content(w.b) }\end{array}$} & & \multicolumn{4}{|c|}{ Surfaces * } \\
\cline { 2 - 6 } & & Plywood & G. & Plastic & Rubber \\
\hline Bani & 9.30 & 0.458 & 0.454 & 0.410 & 0.496 \\
\cline { 2 - 6 } Suwayf & 10.00 & 0.466 & 0.501 & 0.437 & 0.559 \\
\cline { 2 - 6 } & 11.11 & 0.475 & 0.532 & 0.452 & 0.570 \\
\cline { 2 - 6 } & 12.50 & 0.496 & 0.549 & 0.475 & 0.576 \\
\hline \multirow{3}{*}{ Giza 168 } & 9.30 & 0.438 & 0.458 & 0.412 & 0.524 \\
\cline { 2 - 6 } & 10.00 & 0.449 & 0.470 & 0.427 & 0.535 \\
\cline { 2 - 6 } & 11.11 & 0.463 & 0.497 & 0.438 & 0.538 \\
\cline { 2 - 6 } Seds 1 & 12.50 & 0.492 & 0.559 & 0.499 & 0.570 \\
\cline { 2 - 6 } & 9.30 & 0.454 & 0.496 & 0.488 & 0.573 \\
\cline { 2 - 6 } & 10.00 & 0.471 & 0.527 & 0.514 & 0.581 \\
\cline { 2 - 6 } & 11.11 & 0.484 & 0.554 & 0.523 & 0.587 \\
\hline
\end{tabular}

* Significant at $1 \%$ level 
varieties,moisture,surface, varieties between moisture,varieties between surface, moisture between surface, and varieties between surface and moisture interactions. The above variables and the interactios, except the interaction of moisture between surface were significant on the coefficient of friction varieties moisture and surface variables had the main effect on the static friction coefficient. The three varieties belong to the same class of agricultural product,and therefore the effects of moisture, surface and their interaction were also analyzed for each variety. This analysis also showed the same results as above. The effects of moisture and surface were more signifcant than those of the interaction for each varieties .Seds 1 had higher static coefficient of friction than Bani Suwafy 3 and Giza 168 at comparable moisture and on the same surface. The static friction regression coefficients ( $\mathrm{a}$ and $\mathrm{b}$ ) and the percentage of determination coefficients $\left(\mathrm{R}^{2}\right)$ are listed in table (2).

\section{The effect of moisture content:}

The effect of moisture content and surface materials on the static coefficient of friction of Bani Suwayf 3,Giza 168 and Seds 1 are showen in Fig. (2,3 and 4). In the case of Bani Sewef 3,the static coefficient of friction on the Plywood surface varied from 0.458 to 0.496 for moisture contents between $9.30 \%$ and $12.50 \%$ (w.b ), on Galvonized sheet metal from 0.454 to 0.549 , on Plastic from 0.410 to 0.475 and Rubber from 0.496 to 0.576 for the same moisture content . A similar effect of the moisture content on the static-coefficients was also noticed for Giza 168 and Seds 1.

There was a statistically signifcant difference, however among the three varieties for static friction coefficient values .Seds 1 showed the highest static coefficient of friction, followed Giza 168 and Bani Suwayf 3 .

As the moisture content of the varieties increased ,the static coefficient increased (Fig+ 2, 3 and 4). In addition, the interactive effect of varieties $x$ moisture was more significant than any other interactive effect on the static coefficient of the varieties. This shows that moisture has a more significant effect than surface on the static coefficient of friction . 
This is due to the increased adhesion between the varieties and the surface at higher moisture values.

\section{The effect of surface materials:}

The surface materials caused a significant effect on the static coefficient of friction for the three varieties at the same moisture levels. Among the surface materials tested, plastic showed the lowest static

\begin{tabular}{|c|c|c|c|c|c|c|c|c|c|c|c|c|}
\hline \multicolumn{13}{|c|}{ Model : Friction Coefficient $=a+(b \times M)$} \\
\hline \multirow{2}{*}{ Varieties } & \multicolumn{6}{|c|}{ Plywood } & \multicolumn{3}{|c|}{ Galvonized sheet metal } & \multicolumn{2}{|c|}{ Plastic } & \multirow{2}{*}{$\begin{array}{r}\text { Rubb } \\
\text { er } \\
\mathbf{R}^{2}\end{array}$} \\
\hline & a & b & $\mathbf{R}^{2}$ & A & b & $\mathbf{R}^{2}$ & A & B & $\mathbf{R}^{2}$ & A & B & \\
\hline B.S/3 & 0.44 & 0.012 & 0.94 & 0.43 & 0.0 & 0.95 & 0.39 & 0.02 & 0.99 & 0.49 & 0.03 & 0.77 \\
\hline Giza 168 & 0.43 & 0.015 & 0.84 & 0.41 & 0.0 & 0.89 & 0.37 & 0.03 & 0.83 & 0.51 & 0.01 & 0.84 \\
\hline Seds 1 & 0.48 & 0.014 & 0.91 & 0.47 & 0.02 & 0.98 & 0.44 & 0.01 & 0.99 & 0.56 & 0.01 & 0.93 \\
\hline
\end{tabular}

Table (2) : Relationship between static friction coefficient of three wheat varieties and moisture and four surfaces. 
friction coefficient of friction for the three varieties whereas rubber showed the highest values.

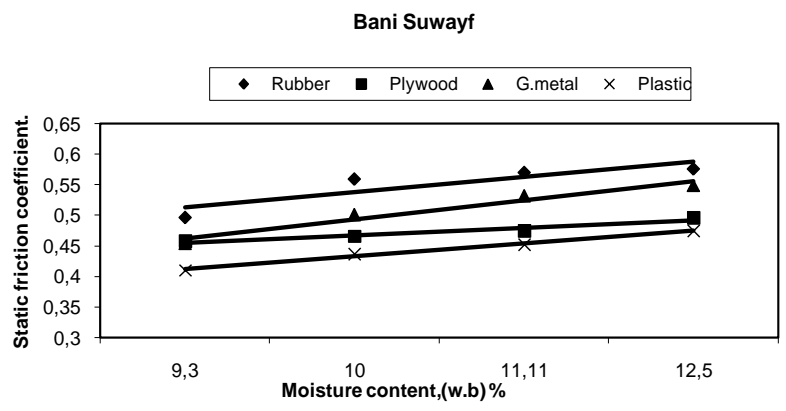

Fig (2) : The effect of moisture content on the static coefficients friction

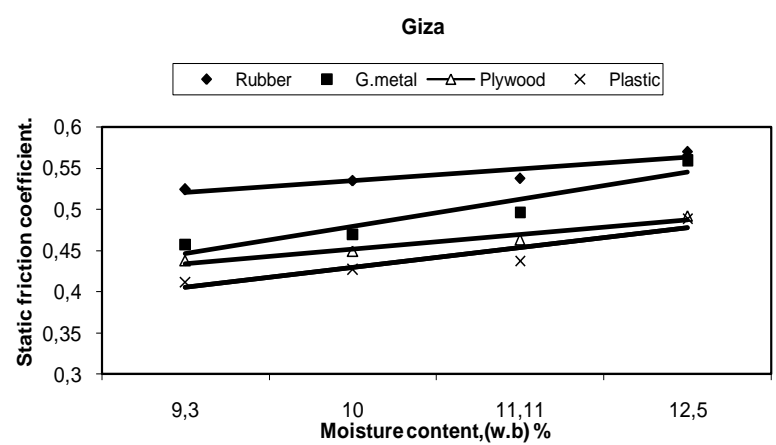

Fig (3) : The effect of moisture content on the static coefficients friction 


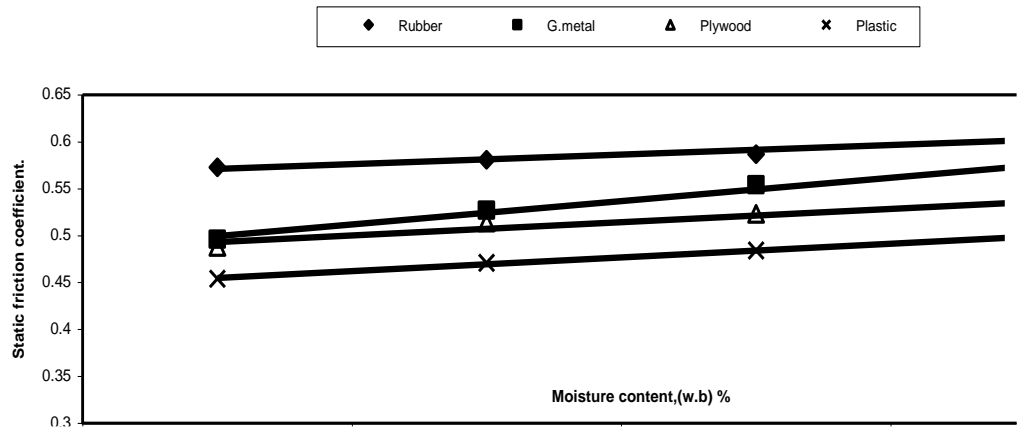

Fig ( 4 ) : The effect of moisture content on the static coefficients friction

\section{CONCLUSIONS}

1- The angle of repose of three wheat varieties with moisture content was linear with positive slope within the range of moisture content under study .

2-The static coefficient of friction generally increased as moisture contents of the varieties increased.

3- Among the surface materials, rubber showed the highest static coefficient of friction for each varieties galvanized metal, plywood and plastic showed the lowest values .

4- Moisture content of the samples was more influential on the static coefficient of friction than surface materials tested.

\section{REFERENCES}

Chakraverty,A. (1972).Post-Harvest Technology of Cereals.Co Pvt,LTD,New Delhi,Bombay,Calcutta .

Helmy, M.A. (1995). Determination of static friction coefficient of some Egyptian agricultural products on various surface.Misr J.Ag. Eng.,12(1):267-281.

Kaleem ,F.H. ;Z.E.Ismail and G.R.Abd Hakim.(1993).Factors affecting grain cleaning efficiency.(part 1): Grain straw mixture and blower characteristics.Misr J. Ag. Eng.10(2):369-382. 
Lawton, P.J.(1980).Coefficients of friction between cereal grain and various silo wall materials.J.Agric.Eng.Res.,25: 75-86.

Mohsnin, N.N.(1970).Physical Properties of Plant and Animal Material.Vol.1,New York, Gordon and Breach Science Publishers.

Soliman, N.S.(1994).Effect of moisture content on angle of repose of paddy rice and its products.Misr,J.Ag.Eng.11(1):163-173.

Snyder, L.N.;W.L.Roller and G.E.Hall.(1967).Coefficients of kintic friction of wheat on various metal surfaces.Trans.of the ASAE, 10(3):411-413,419.

Stewart, B.R.;Q.A.Hossain and O.R.Kunze.(1969).Friction coefficient of Sorghum grain on steel Teflon and concrete surfaces.Trans.of the ASAE.12(4):415-418.

\section{الملخص العربى}

\section{تأثير المحتوى الرطوبى على زاوية المكوث و معامل الأحتكالك للقمح}

$$
\text { د. أشرف كامل زعلوك* - د. فتحى إبراهيم زبادى }
$$

تعتبر زاوية المكوث و معامل الأحتكالك للحبوب من أهم الخواص التى تلعب دورا هاما فى التى

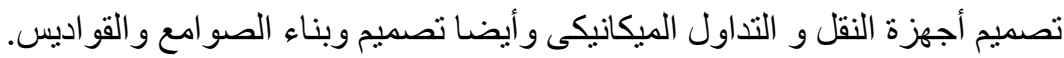

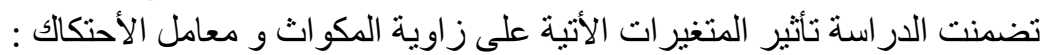

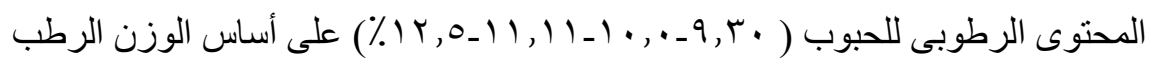

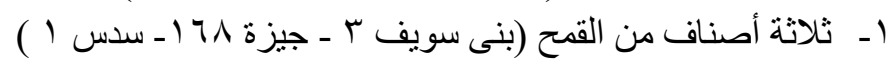

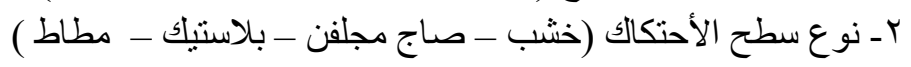
أوضحت النتائج الأتى :-

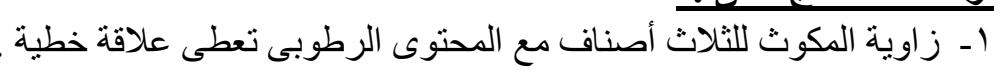

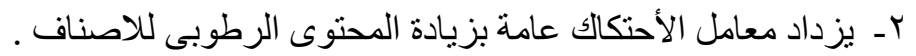

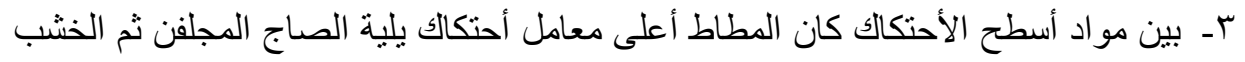

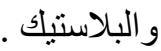
ع - المحتوى الرطوبى بالعينات أكثر نأثير على معامل الأحتكالك من مو اد أسطح الأحتكاك .

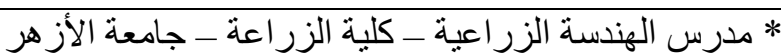

